\title{
Role of Chemotaxis Toward Fusaric Acid in Colonization of Hyphae of Fusarium oxysporum f. sp. radicis-lycopersici by Pseudomonas fluorescens WCS365
}

\author{
Sandra de Weert, Irene Kuiper, Ellen L. Lagendijk, Gerda E. M. Lamers, and Ben J. J. Lugtenberg \\ Leiden University, Institute of Biology, Wassenaarseweg 64, 2333 AL Leiden, The Netherlands \\ Submitted 15 March 2004. Accepted 4 July 2004.
}

Pseudomonas fluorescens WCS365 is an excellent competitive colonizer of tomato root tips after bacterization of seed or seedlings. The strain controls tomato foot and root rot (TFRR) caused by the phytopathogenic fungus Fusarium oxysporum f. sp. radicis-lycopersici. Under biocontrol conditions, fungal hyphae were shown to be colonized by WCS365 bacteria. Because chemotaxis is required for root colonization by WCS365 cells, we studied whether chemotaxis also is required for hyphae colonization. To that end, an in vitro assay was developed to study hyphae colonization by bacteria. The results indicated that cells of the cheA mutant FAJ2060 colonize hyphae less efficiently than cells of wild-type strain WCS365, when single strains were analyzed as well as when both strains were applied together. Cells of WCS365 show a chemotactic response toward the spent growth medium of F. oxysporum f. sp. radicis-lycopersici, but those of its cheA mutant, FAJ2060, did not. Fusaric acid, a secondary metabolite secreted by Fusarium strains, appeared to be an excellent chemo-attractant. Supernatant fluids of a number of Fusarium strains secreting different levels of fusaric acid were tested as chemo-attractants. A positive correlation was found between chemo-attractant activity and fusaric acid level. No chemotactic response was observed toward the low fusaric acid-producer FO242. Nevertheless, the hyphae of FO242 still were colonized by WCS365, suggesting that other metabolites also play a role in this process. The possible function of hyphae colonization for the bacterium is discussed.

Fusarium oxysporum $\mathrm{f}$. sp. radicis-lycopersici is the causal agent of tomato foot and root rot (TFRR) (Brayford 1996; Jarvis 1988). Pseudomonas bacteria such as P. fluorescens WCS365 (Dekkers et al. 1998; Schippers et al. 1987) and P. chlororaphis PCL1391 (Chin-A-Woeng et al. 1998, 2000) can control this disease.

Microscopic analysis has shown that, after mixing of spores through sand, colonization of the plant root by $F$. oxysporum f. sp. radicis-lycopersici starts with attachment of hyphae to root hairs. Subsequently, when hyphae colonize the plant root surface, the junctions between plant cells are

Corresponding author: S. de Weert, Telephone: +31 715275075; Fax: +31 5275088; E-mail: weert@ rulbim.leidenuniv.nl

Current address of I. Kuiper: Nederlands Forensisch Instituut, Volmerlaan 17, 2288 GD Rijswijk, The Netherlands. colonized (Lagopodi et al. 2002). The same sites also are colonized by the two mentioned Pseudomonas biocontrol strains (Bolwerk et al. 2003; Chin-A-Woeng et al. 2000). It is assumed that these sites are colonized because the local concentration of exuded nutrients is high. The pathogenic fungus and the biocontrol bacterium apparently compete for these nutrients (Bolwerk et al. 2003).

We have shown that one of the first steps required for colonization of plant roots by $P$. fluorescens WCS365 bacteria is chemotaxis toward components in root exudate (de Weert et al. 2002). Furthermore, it was shown that $P$. fluorescens WCS365 is able to colonize the hyphae of $F$. oxysporum f. sp. radicislycopersici under biocontrol conditions in the rhizosphere (Bolwerk et al. 2003). Recent studies showed that organic acid and amino acids present in root exudate can function as chemo-attractants (de Weert et al. 2002). Therefore, we tested the hypothesis that chemotaxis also is required for colonization of hyphae. The results are described in this article.

\section{RESULTS AND DISCUSSION}

Influence of $F$. oxysporum $\mathrm{f}$. sp. radicis-lycopersici and chemotaxis on tomato root colonization by $P$. fluorescens WCS365.

The influence of the presence of $F$. oxysporum f. sp. radicislycopersici on tomato root tip colonization by wild-type $P$. fluorescens WCS365 (Table 1), applied on seedlings, was tested in a gnotobiotic quartz sand system (Simons et al. 1996). The level of $F$. oxysporum $\mathrm{f}$. sp. radicis-lycopersici was such that, without the presence of Pseudomonas spp., 70 to $90 \%$ of diseased plants were found, whereas the presence of Pseudomonas spp. reduced that level to 0 to $15 \%$ (Bolwerk et al. 2003). The results showed that the presence of $F$. oxysporum f. sp. radicis-lycopersici had no significant influence on the root tip colonizing abilities of WCS365 (without or with F. oxysporum f. sp. radicis-lycopersici: $5.1 \pm 0.2 \mathrm{a}$ and $5.0 \pm$ $0.3 \mathrm{a}$, respectively, where different letters [a or b] indicate a significant difference). When wild-type strain WCS365 was replaced by its cheA mutant-derivative FAJ2060, the presence of $F$. oxysporum f. sp. radicis-lycopersici decreased the number of bacteria at the root tip by a factor of almost 100 (without or with $F$. oxysporum f. sp. radicis-lycopersici: $4.9 \pm 0.3 \mathrm{a}$ and $3.2 \pm 0.2 \mathrm{~b}$, respectively).

The same experiment also was carried out with auto-fluorescently labeled bacteria. Confocal laser scanning microscopy (CLSM) was used for visualization. Cells of egfplabeled WCS365 were observed as described by Bolwerk and 
associates (2003); many cells were present at the root base where they formed microcolonies. Further toward the root tip, the numbers of cells and microcolonies decreased. F. oxysporum f. sp. radicis-lycopersici had no significant influence on this pattern (data not shown). When the egfp-labeled $c h e A$ mutant FAJ2060 was applied alone in the rhizosphere, the results were equal to those for WCS365, as shown in previous studies (de Weert et al. 2002). However, the presence of $F$. oxysporum f. sp. radicis-lycopersici had a dramatic negative influence on the root-colonizing abilities of the mutant: at the upper root parts compared with egfp-labeled WCS365. The root tip colonizing abilities (determined by CFU counts; discussed below) of the mutant cells $(3.2 \pm 0.2 \mathrm{a})$ were 10 - to 100 -fold lower than those of wild type WCS365 (5.0 $\pm 0.3 \mathrm{~b})$.

The results show that the presence of $F$. oxysporum f. sp. radicis-lycopersici does not influence the colonizing abilities of wild-type WCS365 but heavily decreases the colonizing abilities of the cheA mutant. The wild-type and cheA mutant, when applied alone, have the same root tip colonizing abilities (de Weert et al. 2002); therefore, we conclude that chemotaxis

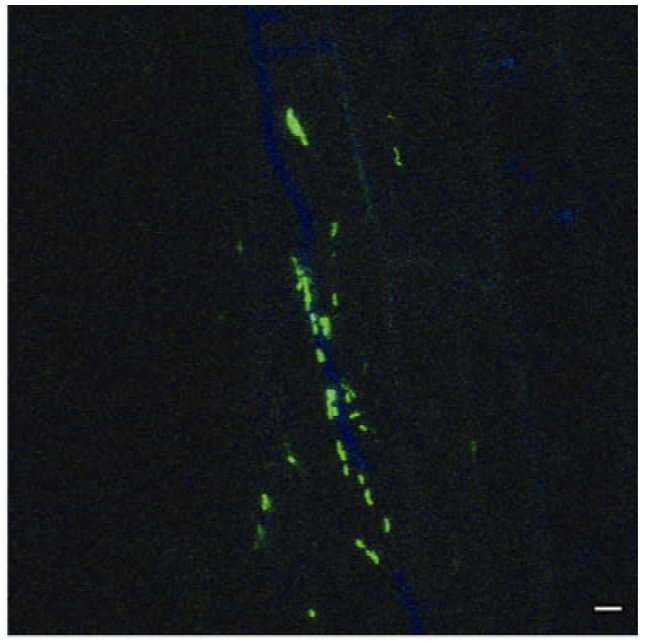

Fig. 1. Confocal laser scanning microscopy analysis of fluorescent Pseudomonas fluorescens WCS365 (egfp) and Fusarium oxysporum f. sp. radicis-lycopersici hyphae (ecfp) in the tomato rhizosphere. The size bar represents $10 \mu \mathrm{m}$. is crucial for the wild type's ability to compete with the fungus for sites on the root. This competition is expected to play an important role in biocontrol (Bolwerk et al. 2003).

\section{Hyphae colonization \\ in the tomato rhizosphere and in vitro.}

Under the conditions described for tomato root tip colonization, we found that $e g f p$-labeled $P$. fluorescens WCS365 cells attached laterally to the $F$. oxysporum f. sp. radicis-lycopersici hyphae, which colonize the tomato rhizosphere, thereby confirming results of Bolwerk and associates (2003) (Fig. 1). However, when the $e g f p$-labeled $c h e A$ mutant was used, the numbers of bacteria on the hyphae were much lower, even to the extent that most hyphae were devoid of bacteria (data not shown). Also, in contrast with the wild type (Fig. 1), cheA mutants did not form microcolonies on the hyphae (data not shown).

The experiment described above has the disadvantage that the presence of $F$. oxysporum f. sp. radicis-lycopersici in the rhizosphere strongly decreases the numbers of $c h e A^{-}$cells in the lower root parts. Therefore, it cannot be excluded that all or part of the difference between wild-type and $c h e A^{-}$cells in colonization of $F$. oxysporum $\mathrm{f}$. sp. radicis-lycopersici hyphae (Fig. 1) is caused by the lower number of $c h e A^{-}$cells available for hyphae colonization. For that reason, we developed a glass slide assay for hyphae colonization in the absence of the tomato root using auto-fluorescent microbes. In this assay (Fig. 2) bacteria were spot inoculated on $F$. oxysporum f. sp. radicislycopersici hyphae and allowed to colonize the growing hyphae for 2 days at $21^{\circ} \mathrm{C}$. Three zones (Fig. 2) were inspected

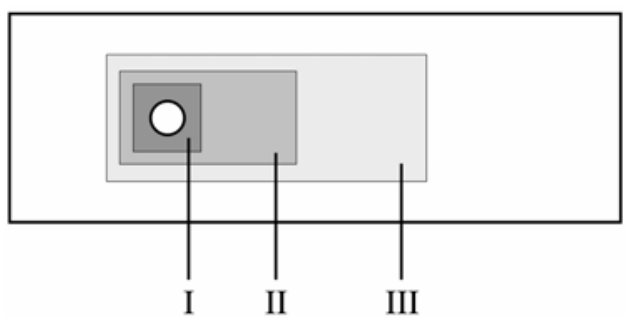

Fig. 2. Schematic view of hyphae colonization assay: zone of spot inoculation (I), zone with dense hyphae networks, (II) and zone where single hyphae are observed (III).

Table 1. Bacterial strains, plasmids, and fungi used in this study

\begin{tabular}{|c|c|c|}
\hline Strains, plasmids, fungi & Relevant characteristics & Reference or source $^{a}$ \\
\hline \multicolumn{3}{|l|}{ Pseudomonas fluorescens } \\
\hline WCS365 & $\begin{array}{l}\text { Wild-type biocontrol strain, efficient competitive colonizer of tomato, potato, and wheat } \\
\text { roots }\end{array}$ & Geels; Schippers; Dekkers \\
\hline FAJ2060 & WCS365 mutant impaired in cheA constructed by single homologous recombination; $\mathrm{Km}^{\mathrm{r}}$ & de Weert et al. 2002 \\
\hline \multicolumn{3}{|c|}{ 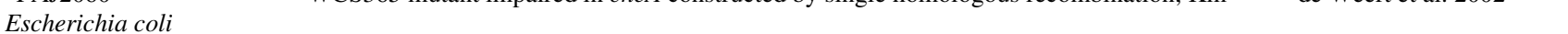 } \\
\hline DH5 $\alpha$ & Used for transformation and propagation of plasmids & Hanahan 1983 \\
\hline \multicolumn{3}{|l|}{ Fungi } \\
\hline ZUM2407b & Cause of foot and root rot on tomato & IPO-DLO \\
\hline FCL64 & F. oxysporum f. sp. radicis-lycopersici ZUM2407 labeled with ecfp & Bolwerk et al. \\
\hline FO47 & F. oxysporum f. sp. radicis-lycopersici; nonpathogenic & Bolwerk et al. \\
\hline FO798 & F. oxysporum, high producer of fusaric acid & Notz et al. 2002 \\
\hline FO801 & F. oxysporum, medium producer of fusaric acid & Notz et al. 2002 \\
\hline $\mathrm{FO} 242$ & F. oxysporum, low producer of fusaric acid & Notz et al. 2002 \\
\hline $\mathrm{FO} 242(e c f p)$ & F. oxysporum, low producer of fusaric acid labeled with ecfp & This study \\
\hline \multicolumn{3}{|c|}{ 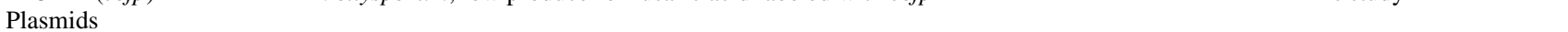 } \\
\hline pMP4662 & pME6010 derivative expressing $r f p$ (dsRED) under the control of the lac promoter & Bloemberg et al. 2000 \\
\hline pMP4655 & pME6010 derivative expressing egfp under the control of the lac promoter & Bloemberg et al. 2000 \\
\hline pMP4650 & pUC21 and pAN 52-1 derivative expressing ecfp & Bolwerk et al. \\
\hline pAN7-1 & Fungal transformation vector based on $\mathrm{Hg}-\mathrm{B}^{\mathrm{r}}$ & Punt et al. 1987 \\
\hline
\end{tabular}

\footnotetext{
${ }^{\mathrm{a}}$ Geels = Geels and Schippers 1983; Schippers = Schippers et al. 1987; Dekkers = Dekkers et al. 2000; IPO-DLO = IPO-DLO, Wageningen, The Netherlands; Bolwerk et al. = A. Bolwerk, A. L. Lagopodi, and A. H. M. Wijfjes, unpublished data

${ }^{\mathrm{b}}$ Fusarium oxysporum f. sp. radicis-lycopersici ZUM2407.
} 
using CLSM. It appeared that egfp-labeled WCS365 cells are able to reach, attach, and colonize the ecfp-labeled $F$. oxysporum f. sp. radicis-lycopersici hyphae in all three zones and form micro-colonies on the hyphae (Fig. 3A and C). In contrast, $e g f p$-labeled cells of $c h e A$ mutant FAJ2060 are present in lower numbers in zone 2 (Fig. 3B) and are hardly observed in zone 3 (Fig. 3D). The mutant cells still formed microcolonies in zone 2 and single cells were attached laterally (Fig. 3B), in contrast to single cells on hyphae in the tomato rhizosphere. Analyzing WCS365 (dsRED) and FAJ2060 (egfp) in competition during hyphae colonization in zone 2 showed that, under these conditions also, FAJ2060 is less competitive than WCS365 (Fig. 4). Mixed colonies between WCS365 and FAJ2060 were formed on the hyphae but FAJ2060 always was present in lower numbers (Fig. 4). Labeling with autofluorescent proteins did not have an effect on bacterial growth (Bloemberg et al. 1997). From these results, it must be concluded that chemotaxis of $P$. fluorescens strain WCS365 is important for the colonization of $F$. oxysporum f. sp. radicislycopersici hyphae. Therefore, we tested whether WCS365 also exerts a chemotactic response toward exudates of hyphae.

Experiments as described for $F$. oxysporum f. sp. radicislycopersici also were performed for colonization of hyphae of the nonpathogenic biocontrol fungus Fusarium FO47 (Table 1). The interactions between WCS365 and its cheA mutant with Fusarium FO47 were equal to those observed for $F$. oxy- sporum f. sp. radicis-lycopersici (data not shown). This suggests that, for the bacterium, chemotaxis-mediated colonization of hyphae is a process to search for a nutrient source and does not function as a defense reaction toward pathogens.

\section{Fusaric acid secreted by $F$. oxysporum f. sp. radicis- lycopersici hyphae is an important chemo-attractant for P. fluorescens WCS365 cells.}

Previously, it already has been concluded that chemotaxis toward tomato root exudate components plays a role in the colonization of tomato roots (de Weert et al. 2002). The chemotaxis drop assay described by Fahrner and associates (1994) as modified by us (de Weert et al. 2002; discussed below) was used to get an impression of which fraction of the hyphae served as chemo-attractants for WCS365 cells. In contrast to washed hyphae, a corresponding amount of culture supernatant $(10 \mu \mathrm{l})$ from $F$. oxysporum f. sp. radicis-lycopersici grown in Armstrong medium initiated a significant chemotactic response of P. fluorescens WCS365 cells within $1 \mathrm{~h}$ (Fig. 5A). Similar results were observed for FO47. In contrast, no chemotactic response was observed toward sterile Armstrong medium (data not shown) or when the cheA mutant FAJ2060 was used instead of wild-type cells (Fig. 5C).

It is known that various Fusarium strains secrete fusaric acid; therefore, this component was tested as a possible chemo-attractant. The results show that wild-type WCS365
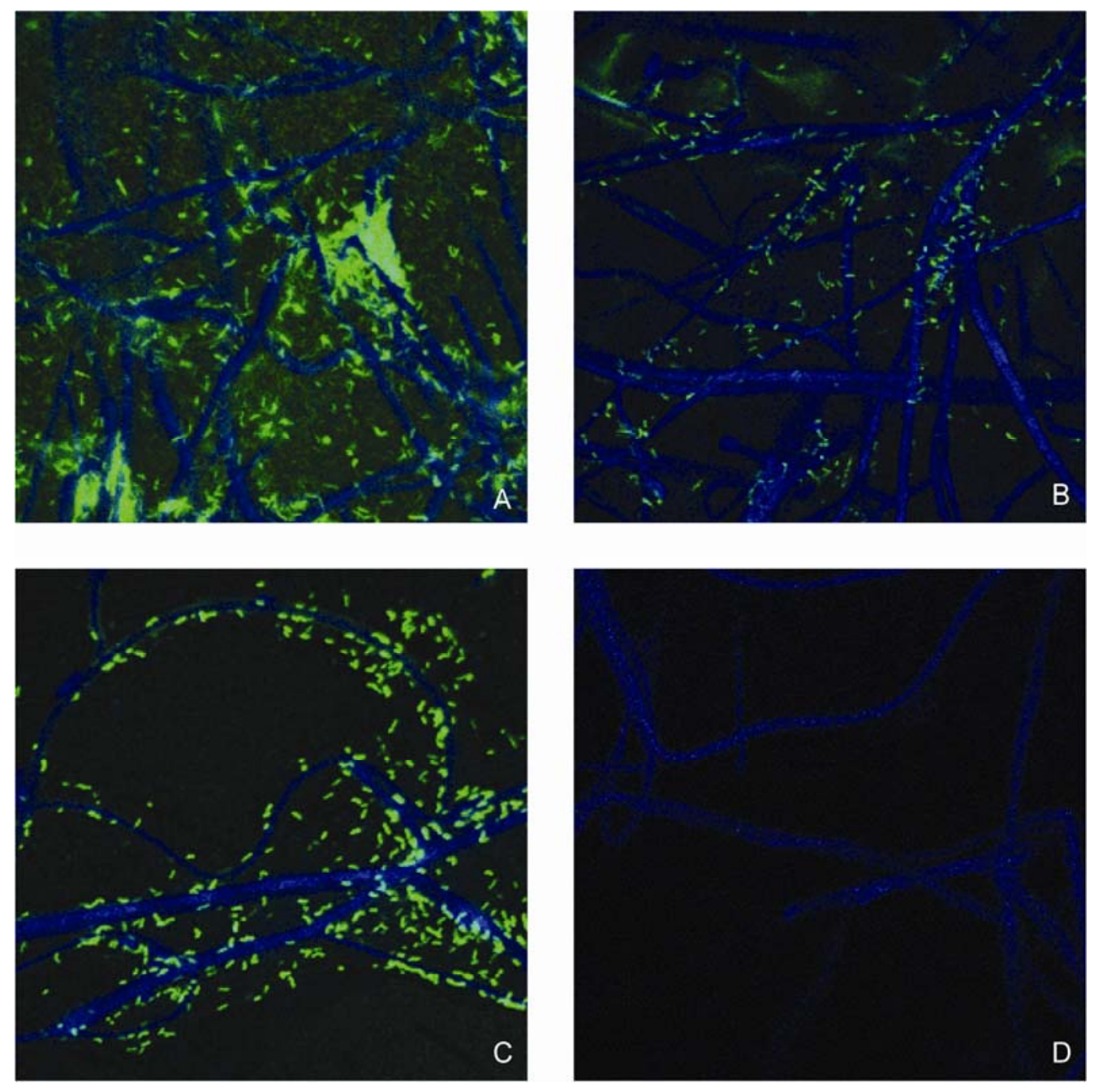

Fig. 3. Confocal laser scanning microscopy analysis of in vitro hyphae colonization. A and B, Wild-type WCS365 (egfp) and FAJ2060 (egfp), respectively, on hyphae of Fusarium oxysporum f. sp. radicis-lycopersici (ecfp) in zone 2. C and D, WCS365 (egfp) and FAJ2060 (egfp), respectively, on hyphae of $F$. oxysporum f. sp. radicis-lycopersici (ecfp) in zone 3. 
cells, but not those of its cheA mutant-derivative FAJ2060, respond chemotactically towards fusaric acid in a concentration in the $10-\mu \mathrm{l}$ drop as low as $8 \mathrm{mM}$ (Fig. 5B). The concentration of the tested chemo-attractant at the site where the chemotactic response is judged is much lower than in the applied drop. It appeared that WCS365 cells could not grow on basic medium (BM) supplemented with fusaric acid (instead of succinic acid) as the sole carbon source (data not shown). Although WCS365 is unable to grow in sterile Armstrong medium, it did grow in culture supernatant of $F$. oxysporum f. sp. radicis-lycopersici which had been cultivated in this medium (data not shown). This result further supports our hypothesis that colonization of hyphae is used as a mechanism to bring bacteria close to a potential nutrient source.

To test whether fusaric acid also plays a role as a (major) chemo-attractant in Fusarium culture supernatants, we tested the chemotactic response of WCS365 cells toward the culture supernatants of three Fusarium strains which secrete different quantities of fusaric acid (Notz et al. 2002). The results (Table 2) show that the supernatant of the high fusaric-acid-producer FO798 initiated the strongest response (after $30 \mathrm{~min}$, a clear ring was observed), followed by that of the medium-level producer FO801 (after $1 \mathrm{~h}$, a clear ring was observed), whereas no response toward supernatant fluids of the low-fusaric-acid-producer FO242 was observed. Controls showed that the chemotaxis mutant FAJ2060 did not respond to any of the tested

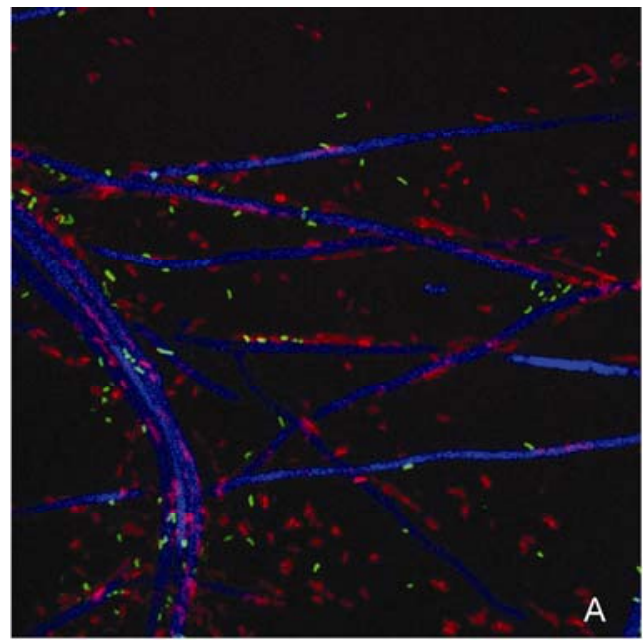

supernatant fluids (data not shown). Although the composition of the culture supernatant fluids of these three different wildtype strains is likely to differ (not only in fusaric acid content), the results suggest that fusaric acid is a major chemo-attractant in the culture supernatant of Fusarium hyphae for P. fluorescens WCS635 cells.

To test whether the three Fusarium strains used above secrete different quantities of fusaric acid under the growth conditions used by us, high-performance liquid chromatography (HPLC) analyses were performed on ethyl acetate extracts of culture supernatants. The latter fractions had the same chemoattractant ability as the culture supernatant from which they were derived. All three strains produced a significant HPLC peak with a retention time indistinguishable from that of commercial fusaric acid. Mixing culture supernatants with commercial fusaric acid still yielded single peaks without a shoulder. Using a calibration curve based on known concentrations of commercial fusaric acid, concentrations of fusaric acid in the culture supernatants were estimated (Table 2). The HPLC peaks of the three strains corresponding in retention time to fusaric acid were dissolved in water and tested for their chemo-attractant ability. All peaks induced a positive reaction. The results confirm that the three strains strongly differ in secreted levels of fusaric acid. Moreover, they show that strain FO242 produces a small but significant amount of fusaric acid (Table 2).

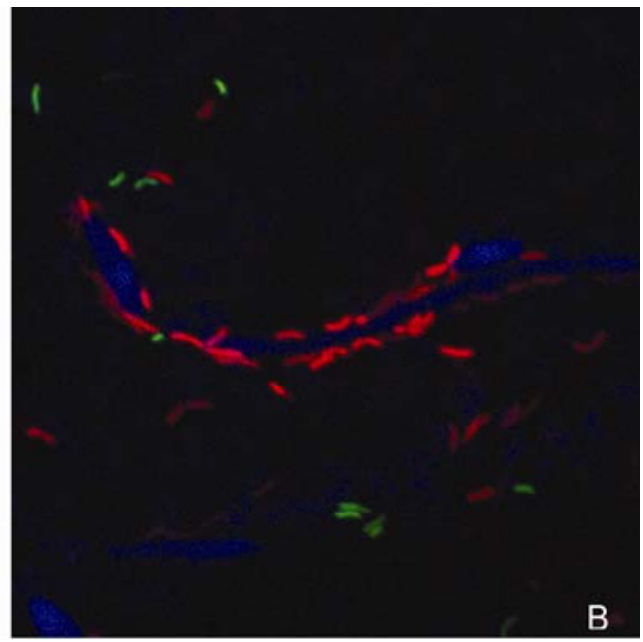

Fig. 4. Confocal laser scanning microscopy analysis of in vitro hyphae colonization. A, Wild-type WCS365 (dsRED) and FAJ2060 (egfp) on hyphae of Fusarium oxysporum f. sp. radicis-lycopersici (ecfp) in zone 2. B, A more detailed view of a microcolony of WCS365 (dsRED) and FAJ2060 (egfp) on hyphae of F. oxysporum f. sp. radicis-lycopersici (ecfp) in zone 2.
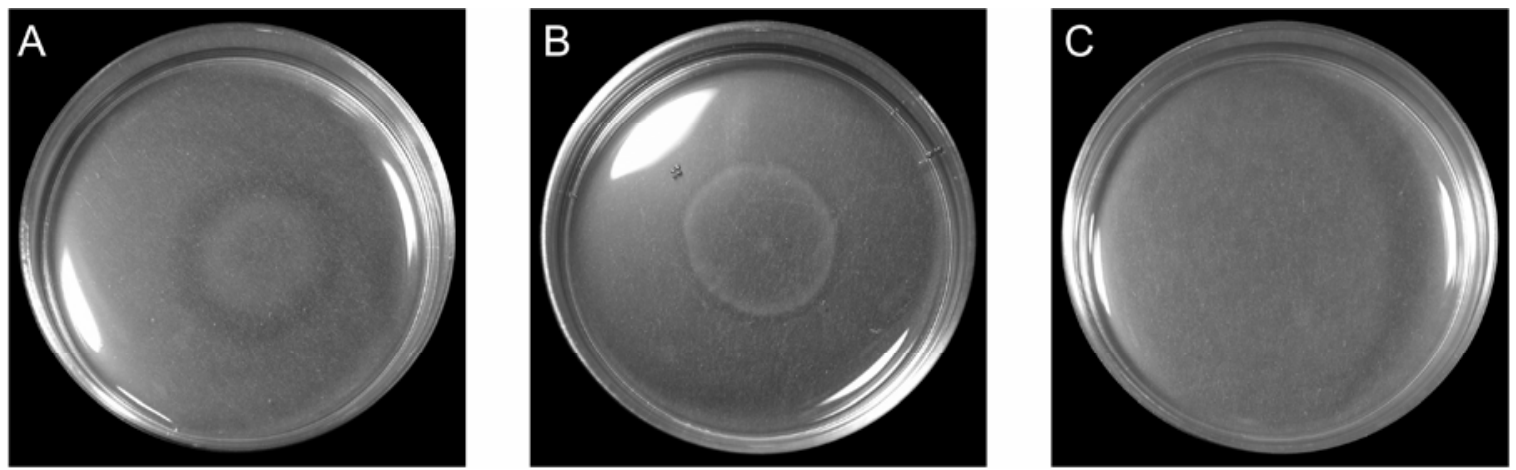

Fig. 5. Chemotactic response of wild-type WCS365 cells toward culture supernatant fluid of A, Fusarium oxysporum f. sp. radicis-lycopersici, B, fusaric acid $(8 \mathrm{mM})$, and $\mathbf{C}$, chemotactic response of its cheA derivative towards the supernatant fluid of $F$. oxysporum f. sp. radicis-lycopersici. Photographs were taken after $1 \mathrm{~h}$ of incubation at room temperature. Putative chemo-attractants were applied as a 10- $\mu \mathrm{l}$ drop. 
Using the same approach as described above, fusaric acid levels secreted by the phytopathogen $F$. oxysporum f. sp. radicis-lycopersici and the TFRR biocontrol strain FO47 were determined. Fusaric acid concentrations produced by $F$. oxysporum $\mathrm{f}$. sp. radicis-lycopersici and FO47 were shown to be at medium levels (Table 2). By mass spectroscopic analyses, it was shown that the collected peaks of $F$. oxysporum f. sp. radicis-lycopersici and FO47 do represent fusaric acid (synthetic fusaric acid: $179.22 \mathrm{~g} \mathrm{~mol}^{-1}$ ) (L. C. Dekkers, personal communication).

Comparing the chemo-attractant activity of dilution series of exudate with known concentrations of fusaric acid and of pure fusaric acid indicated that fusaric acid is not the only chemoattractant (data not shown).

This conclusion was supported by studies of hyphae colonization on Fusarium strain FO242, producing only a small amount of fusaric acid, which was labeled with ecfp (discussed below). No clear difference could be observed between the numbers of WCS365 cells colonizing FO242 hyphae and $F$. oxysporum f. sp. radicis-lycopersici hyphae (data not shown).

From our results, we conclude that $P$. fluorescens biocontrol strain WCS365 colonizes Fusarium hyphae, both in vitro and in the rhizosphere, and chemotaxis is key for this process. Fusaric acid serves as a major chemo-attractant in the colonization of $F$. oxysporum f. sp. radicis-lycopersici. Candidate nutrients are amino acids, organic acids, and sugars because these are known to be secreted by the fungus Macrophomina phaseolina (Singh and Arora 2001). It has been reported previously that arbuscular mycorrhizal (AM) fungi can physically interact with plant-growth-promoting rhizobacteria (Bianciotto et al. 1996). Chemotaxis toward and subsequent colonization of hyphae brings the bacterium closer to nutrients secreted by the fungus.

\section{MATERIALS AND METHODS}

\section{Microorganisms and growth conditions.}

Pseudomonas strains (Table 1) were grown in liquid King's medium B (KB) (King et al. 1954) at $28^{\circ} \mathrm{C}$ under vigorous shaking. When indicated, a synthetic medium, BM, was used (Lugtenberg et al. 2001) with succinic acid (1\%) as the sole carbon source. Media were solidified with 1.8\% agar (Select Agar; Gibco BRL, Life Technologies, Paisley, UK) and, when appropriate, kanamycin (Sigma-Aldrich BV, Zwijndrecht, The Netherlands) was added in a final concentration of $50 \mu \mathrm{g} / \mathrm{ml}$. Escherichia coli was grown at $37^{\circ} \mathrm{C}$ on solidified LuriaBertani medium (Sambrook and Russel 2001)

$F$. oxysporum $\mathrm{f}$. $\mathrm{sp}$. radicis-lycopersici and all other fungi used were grown in liquid Armstrong media (Singleton et al. 1992) at $28^{\circ} \mathrm{C}$ under vigorous shaking. If required, medium was solidified with $1.8 \%$ agar.
Transformation of Fusarium FO242 with ecfp.

Transformation of Fusarium strain $\mathrm{FO} 242$ with ecfp was performed by a polyethylene glycol/ $\mathrm{CaCl}_{2}$-mediated transformation of protoplasts as described by Kistler and Benny (1988) and modified as described by Lagopodi and associates (2002). Two plasmids were used for transformation: pMP4650, containing e $f p$ (A. Bolwerk, A. L. Lagopodi, and A. H. M. Wijfjes, unpublished data), and pAN7-1 (Punt et al. 1987) for Hm-B selection (Lagopodi et al. 2002).

\section{Root-tip colonization assays in a gnotobiotic sand system.}

Root colonization assays were performed as described by Simons and associates (1996) using the gnotobiotic system containing sterile sand to which $10 \%$ (vol/wt) plant nutrient solution (Hoffland et al. 1989) was added to moisten the sand. For colonization experiments, sterile germinated tomato ( $L y$ copersicon esculentum Mill. cv. Carmello; Syngenta, Enkhuizen, The Netherlands) seedlings were inoculated with either the parental strain P. fluorescens WCS365 or its corresponding che $A^{-}$mutant, FAJ2060. The seedlings were placed in the tubes and allowed to grow in a climate-controlled growth chamber at $18^{\circ} \mathrm{C}, 70 \%$ relative humidity, and $16 \mathrm{~h}$ of daylight. F. oxysporum f. sp. radicis-lycopersici was grown for 2 days at $28^{\circ} \mathrm{C}$ in Armstrong medium. Cultures of $100 \mathrm{ml}$ were spun down and washed three times with sterile demineralized water. The obtained spore pellet was resuspended in $20 \mathrm{ml}$ of sterile demineralized water and the spore concentration was determined by counting under a microscope. Spores were mixed through the sand in a concentration of $5 \times 10^{2}$ spores $/ \mathrm{kg}$ of sand. After 7 days, root tips were isolated with adhering sand, and bacteria were removed from the root parts by shaking in $1.0 \mathrm{ml}$ of phosphate buffered saline (PBS). The number of $\mathrm{CFU}$ of parental and mutant cells was determined by plating dilutions on solidified KB medium and on the same medium supplemented with kanamycin. The detection limit was 100 $\mathrm{CFU} / \mathrm{ml}$.

All results were statistically analyzed using the nonparametric Wilcoxon-Mann-Whitney test (Sokal and Rohlf 1981). To avoid $\log 0$ cases, calculations were carried out using log $(\mathrm{CFU}+1) / \mathrm{cm}$ root tip.

\section{CLSM.}

For CLSM studies, the gnotobiotic system was used as described previously with some modifications. Briefly, sterile germinated tomato seedlings were inoculated with cells of strain WCS365 harboring plasmid pMP4655 (expressing egfp). Spores of $F$. oxysporum f. sp. radicis-lycopersici labeled with ecfp (A. Bolwerk, A. L. Lagopodi, and A. H. M. Wijfjes, unpublished data) (FCL64) were mixed through the sand in a concentration of $5 \times 10^{2}$ spores $/ \mathrm{kg}$ of sand. After 5 days of plant growth, roots were washed in PBS and transferred to a cover slip. Samples were examined using an inverted Leica

Table 2. Chemotactic response of Pseudomonas fluorescens WCS365 and its cheA mutant FAJ2060 toward Fusarium culture supernatant fluids and toward fusaric acid

\begin{tabular}{|c|c|c|c|c|}
\hline \multirow[b]{2}{*}{ Fusarium strain } & \multicolumn{2}{|c|}{ Response to $^{a}$} & \multirow[b]{2}{*}{ Fusaric acid concentration $(\mu \mathrm{M})^{\mathrm{c}}$} & \multirow{2}{*}{$\begin{array}{l}\text { Response to } \\
\text { HPLC peak }\end{array}$} \\
\hline & Culture supernatant & Culture supernatant extracts $^{\mathrm{b}}$ & & \\
\hline FO798 & ++ & ++ & 300 & ++ \\
\hline FO801 & + & + & 22 & + \\
\hline $\mathrm{FO} 242$ & - & - & 3 & \pm \\
\hline FORL $^{\mathrm{d}}$ & + & + & 12 & + \\
\hline FO47 & + & + & 8 & + \\
\hline
\end{tabular}

${ }^{a}$ Reponses: ++ = fast response, after $30 \mathrm{~min} ;+=$ significant response, after $1 \mathrm{~h} ; \pm=$ minor response; $-=$ no response.

${ }^{\mathrm{b}}$ Culture supernatants were extracted with ethyl acetate to isolate fusaric acid as described by Notz and associates (2002).

${ }^{\mathrm{c}}$ Concentration of fusaric acid in culture supernatant. High-performance liquid chromatography (HPLC) peak corresponding with the retention time of commercial fusaric acid was quantified based on a standard curve. Peak materials were dried, solubilized in water, and analyzed in the chemotaxis "drop" assay.

${ }^{\mathrm{d}}$ FORL $=$ Fusarium oxysporum $\mathrm{f}$. sp. radicis-lycopersici . 
CLSM (DMIRBE-SP, Leica, Germany) equipped with an argon laser for eGFP visualization (excitation $488 \mathrm{~nm}$ and emission 501 to $540 \mathrm{~nm}$ ) and eCFP visualization (excitation $457 \mathrm{~nm}$ and emission 466 to $490 \mathrm{~nm}$ ), and a krypton laser (excitation 568 $\mathrm{nm}$ and emission 575 to $600 \mathrm{~nm}$ ) for dsRED visualization. Images were obtained by sequential scan analyses. The projections obtained were processed using Adobe PhotoShop 6.

\section{In vitro hyphae colonization studies.}

Hyphae colonization studies in the absence of the root were performed by spreading $1.8 \%$ Armstrong agar medium (150 $\mu \mathrm{l}$ ) on an object slide ( 25 by 15 by $1.5 \mathrm{~mm}$ ). A 2 -mm-diameter plug of $F$. oxysporum f. sp. radicis-lycopersici labeled with ecfp and grown on Armstrong plates was placed on the agar layer. Bacteria grown overnight and labeled with egfp or $d s R E D$ were set to an optical density at $620 \mathrm{~nm}\left(\mathrm{OD}_{620}\right)$ value of $0.1 \mathrm{in} 10 \mathrm{ml}$ of PBS. Of this mixture, a volume of $1.0 \mathrm{ml}$ was spun down and resuspended in $10 \mu \mathrm{l}$ of PBS. Bacteria were spotted as a $1-\mu \mathrm{l}$ drop $\left(10^{6}\right.$ to $10^{7}$ cells) on the plug of a Fusarium sp. Object slides were placed in a sterile petri dish containing wet filter paper, closed with parafilm, and incubated for 2 to 3 days at $21^{\circ} \mathrm{C}$. Slides were used for confocal studies as described previously.

\section{Chemotaxis experiments.}

Chemotaxis experiments were performed using the "drop" assay of Fahrner and associates (1994) as described by Grimm and Harwood (1997) with slight modifications. Briefly, cells grown overnight in $\mathrm{KB}$ were diluted 100-fold into $150 \mathrm{ml}$ of $\mathrm{BM}$ containing $1 \%$ succinic acid. When cells reached the early logarithmic phase $\left(\mathrm{OD}_{600}\right.$ of 0.12$), 40-\mathrm{ml}$ samples were gently spun down $(3,000 \mathrm{rpm})$ and resuspended in $12 \mathrm{ml}$ of chemotaxis buffer $(100 \mathrm{mM}$ potassium phosphate, $\mathrm{pH} 7.0,20 \mu \mathrm{M}$ EDTA).

An aqueous solution of $1 \%$ hydroxypropylmethylcellulose (Sigma-Aldrich), formulated to give a viscosity of approximately $4,000 \mathrm{cP}$ in a $2 \%$ aqueous solution, was added to the cell suspension to give a final volume of $15 \mathrm{ml}$. The resulting cell suspension was transferred to a 60 -mm-diameter petri dish in which it formed a layer approximately $3 \mathrm{~mm}$ thick. Supernatant fluid of Fusarium spp. grown in Armstrong medium, fusaric acid $(0.5 \mathrm{mg} / \mathrm{ml}$ in water), extracts, or purified peak material from HPLC analyses were added to the center of the dish as 10- $\mu$ l droplets. During incubation for up to 2 hours at room temperature, the plates were analyzed for the appearance of a clear zone. The bacteria attracted by the added chemoattractant leave a clear zone where they were previously sited.

\section{Extraction of fusaric acid and HPLC analyses.}

Extractions of fusaric acid from supernatant fluids of Fusarium spp. were performed as described by Notz and associates (2002) with some modifications. Briefly, $100 \mathrm{ml}$ of Armstrong medium was inoculated with two plugs of a Fusarium sp. grown on Armstrong plates. After incubation at $28^{\circ} \mathrm{C}$ for 2 days, supernatant fluids were filtered using miracloth and 50 $\mathrm{ml}$ of the filtrate was spun down for $10 \mathrm{~min}$ at 4,000 rpm. After centrifugation, the supernatants were acidified to $\mathrm{pH} 2$ using 2N HCL. Subsequently, one volume of ethyl acetate $(50 \mathrm{ml})$ (Fluka Chemie, Zwijdrecht, The Netherlands) was added and mixtures were shaken for $5 \mathrm{~min}$. The organic phase was separated from the aqueous phase by centrifugation for $10 \mathrm{~min}$ at $4,000 \mathrm{rpm}$. The organic phase was dried using a rotor-vapor and the resulting pellet was dissolved in $1.0 \mathrm{ml}$ of methanol. This sample was analyzed using HPLC (Jasco International Co. Ltd., Tokyo) equipped with a reversed phase Econosphere C18 column, $5 \mu \mathrm{m}, 250$ by $4.6 \mathrm{~mm}$ (Alltech, Breda, The Netherlands) at room temperature. Samples of 30 to $50 \mu \mathrm{l}$ mixed with
$20 \%$ acetonitrile (Labscan Ltd., Dublin, Ireland) in water were eluted with a linear 20 to $80 \%$ gradient of acetonitrile and water acidified with $0.1 \%$ Trifluoroacetic acid (SigmaAldrich) over $35 \mathrm{~min}$. Fractions were collected every minute, and fusaric acid was detected by monitoring absorbance at 270 nm using a Jasco MD-910 multiwave length detector (Jasco International Co. Ltd.). At a flow rate of $1.0 \mathrm{ml} / \mathrm{min}$, the retention time of fusaric acid was $8 \mathrm{~min}$. The samples were quantified using a standard curve of commercially available synthetic fusaric acid (Acros Organics, Geel, Belgium).

\section{ACKNOWLEDGMENTS}

This research was supported by the EU-BIOTECH FW5 project QLRT2002-00914. We thank R. Notz and G. Défago for providing Fusarium strains FO798, FO801, and FO242; and L. C. Dekkers for mass spectrometric analysis.

\section{LITERATURE CITED}

Bianciotto, V., Minerdi, D., Perotto, S., and Bonfante, P. 1996. Cellular interactions between arbuscular mycorrhizal fungi and rhizosphere bacteria. Protoplasma 193:123-131.

Bloemberg, G. V., O’Toole, G. A., Lugtenberg, B. J., and Kolter, R. 1997. Green fluorescent protein as a marker for Pseudomonas spp. Appl. Environ. Microbiol 63:4543-4551.

Bloemberg, G. V., Wijfjes, A. H. M., Lamers, G. E. M., Stuurman, N., and Lugtenberg, B. J. J. 2000. Simultaneous imaging of Pseudomonas fluorescens WCS365 populations expressing three different autofluorescent proteins in the rhizosphere: new perspectives for studying microbial communities. Mol. Plant-Microbe Interact. 13:1170-1176.

Bolwerk, A., Lagopodi, A. L., Wijfjes, A. H. M., Lamers, G. E. M., ChinA-Woeng, T. F. C., Lugtenberg, B. J. J., and Bloemberg, G. V. 2003. Interactions in the tomato rhizosphere of two Pseudomonas biocontrol strains with the phytopathogenic fungus Fusarium oxysporum f. sp. radicis-lycopersici. Mol. Plant-Microbe Interact. 16:983-993.

Brayford, D. 1996. Fusarium oxysporum f. sp. radicis-lycopersici, IMI description of fungi and bacteria no. 1270. Mycopathologia 133:61-63.

Chin-A-Woeng, T. F. C., Bloemberg, G. V., Mulders, I. H. M., Dekkers, L. C., and Lugtenberg, B. J. J. 2000. Root colonization by phenazine-1carboxamide-producing bacterium Pseudomonas chlororaphis PCL1391 is essential for biocontrol of tomato foot and root rot. Mol. Plant-Microbe Interact. 13:1340-1345.

Chin-A-Woeng, T. F. C., Bloemberg, G. V., van der Bij, A. J., van der Drift, K. M. G. M., Schripsema, J., Kroon, B., Scheffer, R. J., Keel, C., Bakker, P. A. H. M., Tichy, H. V., de Bruin, F. J., Thomas-Oates, J. E., and Lugtenberg, B. J. J. 1998. Biocontrol by pehnazine-1-carboxamideproducing Pseudomonas chlororaphis PCL1391 of tomato root rot caused by Fusarium oxysporum f. sp. radicis lycopersici. Mol. PlantMicrobe Interact. 11:1069-1077.

Dekkers, L. C., Bloemendaal, C. J., de Weger, L. A., Wijffelman, C. A., Spaink, H. P., and Lugtenberg, B. J. J. 1998. A two-component system plays an important role in the root-colonizing ability of Pseudomonas fluorescens strain WCS365. Mol. Plant-Microbe Interact. 11:45-56.

Dekkers, L. C., Mulders, I. H. M., Phoelich, C. C., Chin, A. W.-T., Wijfjes, A. H. M., and Lugtenberg, B. J. J. 2000. The sss colonization gene of the tomato-Fusarium oxysporum $\mathrm{f}$. $\mathrm{sp}$ radicis-lycopersici biocontrol strain Pseudomonas fluorescens WCS365 can improve root colonization of other wild-type Pseudomonas spp. bacteria. Mol. Plant-Microbe Interact. 13:1177-1183.

de Weert, S., Vermeiren, H., Mulders, I. H. M., Kuiper, I., Hendrickx, N., Bloemberg, G. V., Vanderleyden, J., de Mot, R., and Lugtenberg, B. J. J. 2002. Flagella-driven chemotaxis towards exudate components is an important trait for tomato root colonization by Pseudomonas fluorescens. Mol. Plant-Microbe Interact. 15:1173-1180.

Fahrner, K. A., Block, S. M., Krishnaswamy, S., Parkinson, J. S., and Berg, H. C. 1994. A mutant hook-associated protein (HAP3) facilitates torsionally induced transformations of the flagellar filament of Escherichia coli 3. J. Mol. Biol. 238:173-186.

Geels, F. P., and Schippers, B. 1983. Reduction of yield depressions in high frequency potato cropping soil after seed tuber treatments with antagonistic fluorescent Pseudomonas spp. Phytopathology 108:207-214.

Grimm, A. C., and Harwood, C. S. 1997. Chemotaxis of Pseudomonas spp. to the polyaromatic hydrocarbon naphthalene. Appl. Environ. Microbiol. 63:4111-4115.

Hanahan, D. 1983. Studies on transformation of Escherichia coli with plasmids. J. Mol. Biol. 166:557-580. 
Hoffland, E., Findenegg, G. R., and Nelemans, J. A. 1989. Solubilization of rock phosphate by rape. Plant Soil 113:161-165.

Jarvis, W. R. 1988. Fusarium crown and root rot on tomatoes. Phytoprotection 69:49-64.

King, E. O., Ward, M. K., and Raney, D. E. 1954. Two simple media for the demonstration of pyocyanin and fluorescin. J. Lab. Clin. Med. 44:301-307

Kistler, H. C., and Benny, U. K. 1988. Genetic transformation of the fungal wilt pathogen Fusarium oxysporum. Curr. Genet. 13:145-149.

Lagopodi, A. L., Ram, A. F. J., Lamers, G. E., Punt, P. J., Van den Hondel, C. A. M. J. J., Lugtenberg, B. J. J., and Bloemberg, G. V. 2002. Novel aspects of tomato root colonization and infection by Fusarium oxysporum f. sp. radicis-lycopersici revealed by confocal laser scanning microscopic analysis using the green fluorescent protein as a marker. Mol. Plant-Microbe Interact. 15:172-179.

Lugtenberg, B. J., Dekkers, L. C., and Bloemberg, G. V. 2001. Molecular determinations of rhizosphere colonization by Pseudomonas. Annu. Rev. Phytopathol. 39:461-490.

Notz, R., Maurhofer, M., Dubach, H., Haas, D., and Defago, G. 2002. Fusaric acid-producing strains of Fusarium oxysporum alter 2,4-diacetylphloroglucinol biosynthetic gene expression in Pseudomonas fluorescens $\mathrm{CHA} 0$ in vitro and in the rhizosphere of wheat 1 . Appl. Environ.
Microbiol. 68:2229-2235.

Punt, P. J., Oliver, R. P., Dingemanse, M. A., Pouwels, P. H., and van den Hondel, C. A. 1987. Transformation of Aspergillus based on the hygromycin B resistance marker from Escherichia coli. Gene 56:117124.

Sambrook, J., and Russel, D. 2001. Molecular Cloning: A Laboratory Manual. Cold Spring Harbor Laboratory Press, Cold Spring Harbor NY, U.S.A.

Schippers, B., Bakker, A. W., and Bakker, P. A. H. M. 1987. Interactions of deleterious and beneficial rhizosphere microorganisms and the effect of cropping practices. Annu. Rev. Phytopathol. 25:339-358.

Simons, M., van der Bij, A. J., Brand, I., de Weger, L. A., Wijffelman, C. A., and Lugtenberg, B. J. J. 1996. Gnotobiotic system for studying rhizosphere colonization by plant growth promoting Pseudomonas bacteria. Mol. Plant-Microbe Interact. 9:600-607.

Singh, T., and Arora, D. K. 2001. Motility and chemotactic response of Pseudomonas fluorescens toward chemoattractants present in the exudate of Macrophomina phaseolina. Microbiol. Res. 156:343-351.

Singleton, L. L., Mihail, J. D., and Rush, C. M. 1992. Methods for Research on Soilborne Phytopathogenic Fungi. American Phytopathological Society, St. Paul, MN, U.S.A.

Sokal, R. R., and Rohlf, F. J. 1981. Biometry. Freeman, San Francisco. 